\title{
Modeling of cutting forces in trochoidal milling with respect to wear-dependent topographic changes
}

\author{
Jim A. Bergmann ${ }^{1}$ (1) $\cdot$ Nils Potthoff $^{1} \cdot$ Tobias Rickhoff $^{1} \cdot$ Petra Wiederkehr $^{1}$
}

Received: 22 March 2021 / Accepted: 10 May 2021 / Published online: 24 May 2021

(c) The Author(s) 2021

\begin{abstract}
The aerospace industry utilizes nickel-based super-alloys due to its high level of strength and corrosion resistance. To evaluate milling strategies regarding tool wear, the prediction of forces during these cutting operations is essential. This comprises the determination of the undeformed chip thickness. Due to the complex interdependencies of tool engagements, the determination of these thicknesses is challenging. A geometric physically-based simulation system was extended by a novel time-discrete envelope model to increase the precision of the calculated undeformed chip thicknesses. In order to take tool wear into account, digitized topographies of cutting inserts in different states of tool wear were modelled.
\end{abstract}

Keywords Geometric modeling $\cdot$ Tool wear · Topographies $\cdot$ Inconel

\section{Introduction}

Nickel-based super-alloys are widely used in the energy and aerospace industry. Difficult-to-cut materials, like Inconel 718, are characterized by a high strength and corrosion resistance, even at high temperatures, which make them especially popular in these sectors $[1,2]$. However, the machining of such materials is difficult as the material tends to cause high process forces and high tool wear [3]. One possibilty to improve the productivity and the tool life is the utilization of alternative path strategies, e.g., trochoidal milling $[4,5]$, which exhibit more favorable wear progressions than linear path milling strategies [6]. Regarding the complex engagement situation in trochoidal milling and optimization of the process, a simulation-based analysis is

The investigations are based on the research project "Virtual Machining" (PE-216-0024), which is kindly funded by the Stiftung Mercator and the Mercator Research Center Ruhr, and on the research project "Stochastic Modeling of the Interaction of Tool Wear and the Machining Affected Zone in Nickel-Based Superalloys and Application in Dynamic Stability" (400845424), which is kindly funded by the German Research Foundation (DFG).

Jim A. Bergmann

jim.bergmann@tu-dortmund.de

1 Virtual Machining, TU Dortmund University, Otto-Hahn-Straße 12, 44227 Dortmund, Germany required, especially when the consideration of tool wear is of special interest. Therefore, models for turning and drilling were presented in several studies that take tool wear into account by using finite element analysis [7, 8].

While simulation systems have been used to predict force evolution for milling processes or evaluate the dynamic process behavior $[9,10]$, the developed models are restricted to specific cases for which they have been calibrated. An essential process characteristic is the resulting chip thickness during machining, which can be used to predict process forces. Especially for the analysis of process stability and tool wear, a precise prognosis of the occurring chip thicknesses is needed [11-13]. The determination of so called undeformed chip thicknesses during cutting operations has been subject to various abstractions to ensure feasibility in regard to simulations of whole processes [14]. Empirical models can be used, based on assumptions derived from orthogonal cutting operations and their prevalent chip thickness [15]. These models can be applied to a discretized tool model to result in a global process force calculated for each time step. The prediction of chip thicknesses during milling operations based on the Constructive-Solid-Geometry technique [10] can also be used, when neglecting effects of tool wear or variations of the cutting edge. Other approaches considered tool wear by modifying force model parameter values for each tool wear state $[16,17]$ or extending the force model with an additional wear-dependent parameter [18]. The calculation 
Table 1 Chemical composition of Inconel 718 (2.4668) specified in wt\% according to the manufacturer

\begin{tabular}{llllllll}
\hline $\mathrm{C}$ & $\mathrm{Si}$ & $\mathrm{Mn}$ & $\mathrm{P}$ & $\mathrm{S}$ & $\mathrm{Cr}$ & $\mathrm{Mo}$ \\
\hline 0.039 & 0.05 & 0.05 & 0.012 & 0.0003 & 17.67 & 2.98 & $\mathrm{Ni}$ \\
\hline $\mathrm{Co}$ & $\mathrm{Cu}$ & $\mathrm{Nb}$ & $\mathrm{Ti}$ & $\mathrm{Fe}$ & $\mathrm{Al}$ & $\mathrm{B}$ & $\mathrm{Ta}$ \\
\hline 0.40 & 0.04 & 5.41 & 0.930 & 17.50 & 0.49 & 0.0028 \\
\hline
\end{tabular}

of process forces for trochoidal milling strategies have been investigated using numerical models, which derived parameter values specifically for trochoidal path strategies $[19,20]$, since the transferability of force parameter values from linear strategies to trochoidal milling could not be achieved [21]. However, tool wear was not considered in these studies. Due to the complex engagement situation of trochoidal paths and the wear-dependent change of the shapes of cutting tools, the prediction of process forces is limited with previous methods, when considering tool wear-specifically to trochoidal milling strategies. In this investigation, a new modeling approach is presented, which utilizes different states of tool wear derived from trochoidal milling strategies to increase the precision of the calculated process forces in an existing geometric physically-based simulation system. Instead of using wear-specific process force parameter values, the topography of the tool is taken into account, allowing for a calibration based on linear path strategy experiments. A time-discrete envelope model is applied to predict process forces for linear path and trochoidal path strategies in Inconel 718 using a novel tool model. The new model is based on the consideration of individual cutting segments in combination with a discrete workpiece representation.

\section{Materials and methods}

In this section, the experimental setup and the measuring equipment used is described. In addition, the method for digitizing cutting insert is explained in detail.

\subsection{Experimental setup}

In order to detect different tool wear stages and their effect on process forces, milling experiments were conducted on a five-axis machining center, Deckel Maho DMU50 eVolution. The spindle speed is limited to $\mathrm{n}=18,0001 / \mathrm{min}$ with a maximum feed rate for each axis of $v_{f}=20,000 \mathrm{~mm} / \mathrm{min}$. Due to the high torque absorption of $\mathrm{T}=130 \mathrm{Nm}$ the machine is suitable for the machining of nickel-based superalloys [22].

The experiments were carried out using milling tools with carbide cutting inserts and a nominal tool diameter of $\mathrm{d}=16 \mathrm{~mm}$. The inserts had a corner radius of $\mathrm{r}=0.8 \mathrm{~mm}$. To increase tool life, inserts with a multilayer PVD-AlTiCrN coating were used (Sandvik Coromant R390-11 T3 08MPM 1130) in combination with lubricant coolant. The workpiece material consisted of the forged nickel-based superalloy Inconel 718 (2.4668) (Table 1). The experimental setup consisted of several components. For the experimental setup, a three-component dynamometer of the type Kistler 9139 was mounted on the machine table via an adapter plate to measure the process forces. The data was recorded using a measuring amplifier with a sampling frequency of $20 \mathrm{kHz}$. The workpiece with dimensions of $38 \times 107 \times 65 \mathrm{~mm}^{3}$ was fixed on the dynamometer with a clamping device. The experimental setup is shown in Fig. 1. To record different wear states during the tests, a digitization of the cutting insert was conducted at an early stage (material removal of $V_{w, 0}=0 \mathrm{~mm}^{3}$ ) and a steady state stage $\left(V_{w, 1}=2140 \mathrm{~mm}^{3}\right)$. In addition, a late stage with a material removal of $V_{w, 2}=5350 \mathrm{~mm}^{3}$ was digitized, representing a defined end of tool life (Sect. 2.3). For this investigation, the state of a new and a worn cutting insert was chosen for further evaluation.

\subsection{Calibration experiments}

In order to determine force parameter values for the proposed force model, calibration tests using linear path milling experiments were carried out using two different wear states $\left(\mathrm{V}_{w, 1}\right.$ and $\left.\mathrm{V}_{w, 2}\right)$. Within these force measurement tests, linear paths were machined. For the initialization of the process force model, new cutting inserts were utilized. For the

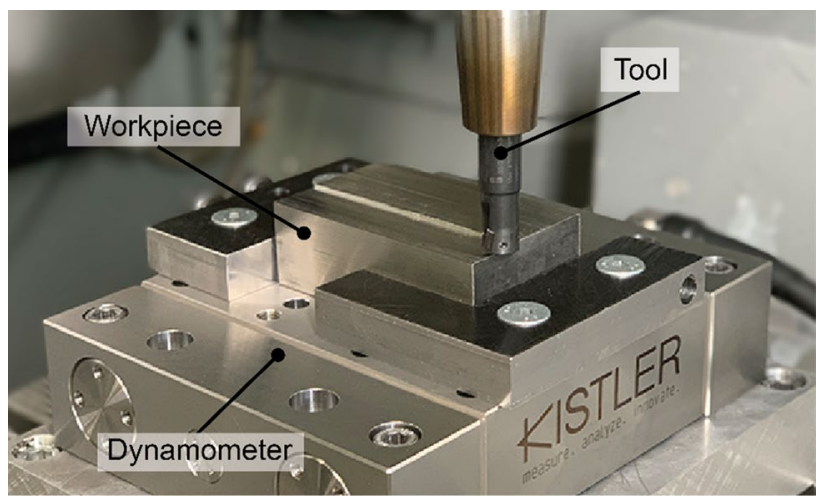

Fig. 1 Experimental setup for a linear milling path 
consideration of tool wear, a cutting insert in a late stage was chosen, showing an increase of process forces during cutting. For these tests, a cutting velocity of $v_{c}=30 \mathrm{~m} / \mathrm{min}$ with a tooth feed of $f_{z}=0.12 \mathrm{~mm}$ was used and a depth of cut of $a_{p}=1 \mathrm{~mm}$ and width of cut of $a_{e}=1 \mathrm{~mm}$ was chosen. The experiments were conducted using a trochoidal path strategy with a cutting velocity of $v_{c}=40 \mathrm{~m} / \mathrm{min}$ and a feed per tooth of $f_{z}=0.1 \mathrm{~mm}$ while maintaining the same depth of cut of $a_{p}=1 \mathrm{~mm}$ and width of cut of $a_{e}=1 \mathrm{~mm}$. The process parameter values were chosen based on previous investigations [6].

\subsection{Digitization of tool inserts}

For the determination of the tool model, digitizations of the considered cutting inserts were required. To achieve comparable measurements within the conducted test series, an accurate positioning with high repeatability is important. Therefore, a negative imprint of the inserts used was created using imprint mass to avoid the removal of cutting inserts within the test series. In addition to the experimental setup, a holder device with replaceable elements was designed. These replaceable elements, in the following referred to as imprint holders, were produced with a 3D printer. The holder device was mounted on the machine table, allowing for an easy replacement of imprint holders. Figure 2 illustrates the process of acquiring an imprint of the cutting insert (a) and the result (b), which represents the digitized insert. The replicated part and a microscopic image of the cutting insert is shown in
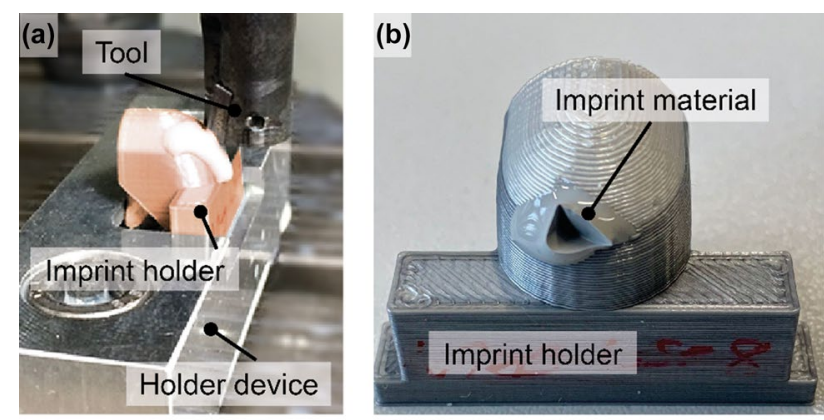

(c)

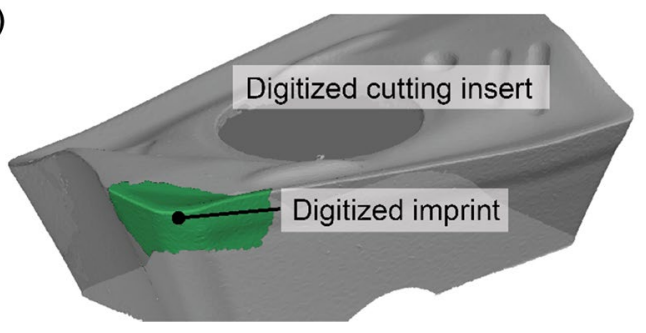

Fig. 2 Illustration of a the imprinting process using an imprint holder (highlighted orange) placed in the holder device, $\mathbf{b}$ the negative imprint and $\mathbf{c}$ and the resulting digitized cutting edge
Fig. 2c. By using this approach, a negative of the cutting insert could be built directly on the machining center and different states of wear could be recorded. The digitization of the imprints was conducted with the optical 3D measurement system Alicona Infinite Focus G5. The two selected wear states are shown in Fig. 3.

\section{Calculation of trochoidal paths}

The motion of the trochoidal path can be described as a superposition of a circular motion with a linear movement of the tool. In literature, different approaches for the calculation of trochoidal path were compared, e.g., a circular and trochoidal model by Rauch et al. [23] or the epicycloidal model by Salehi et al. [24]. In this paper, the calculation of X-and Y-coordinates of the tool center point along the path is given by

$x_{c}=B \cdot \cos (\theta)$,

$y_{c}=B \cdot \sin (\theta)+\frac{S_{o} \cdot \theta}{2 \pi}$,

with a tool diameter $\mathrm{D}=16 \mathrm{~mm}$, the step over $S_{\mathrm{O}}=1 \mathrm{~mm}$ and the path angle $\theta$. B can be calculated with $\mathrm{B}=\left(S_{w}-\mathrm{D}\right) / 2$, where $S_{w}$ is the slot width of $50 \mathrm{~mm}$. The movement of the cutting edges is realized by the rotational axis of the tool spindle. The use of trochoidal path strategies results in a complex engagement situation which leads to variable undeformed chip thicknesses. While linear machining (Fig. 4a) creates constant maximum chip thicknesses, the use of trochoidal paths (Fig. 4c) generates varying maximum chip thicknesses along the path. In Fig. $4 \mathrm{~b}$ a comparison of both strategies shows a reduction of the resulting maximum chip thicknesses through the process.

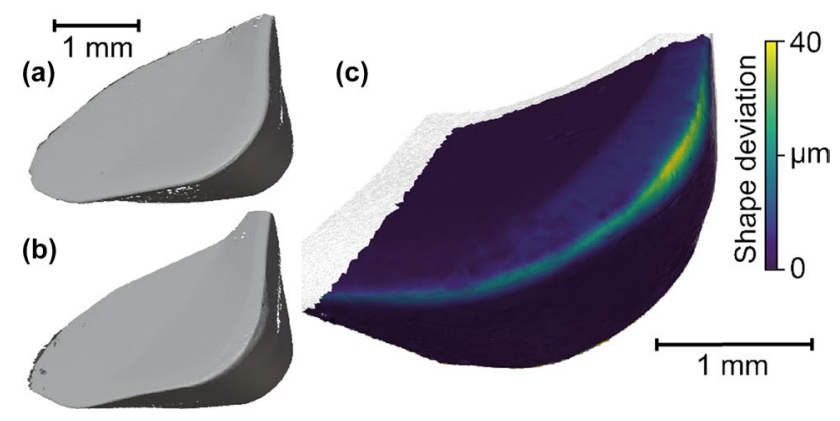

Fig. 3 Measurement of the digitized cutting inserts. a A new cutting insert $\left(V_{w, 0}\right)$ and $\mathbf{b}$ a worn cutting insert $\left(V_{w, 2}\right)$, c with shape deviations of up to $40 \mu \mathrm{m}$ due to tool wear 


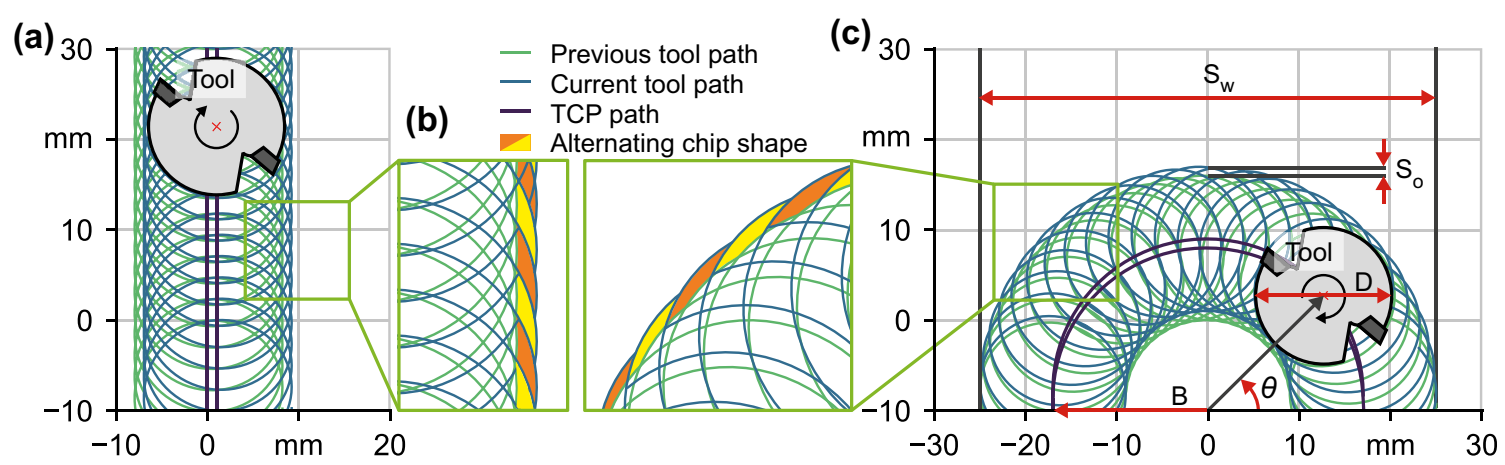

Fig. 4 Comparison of a $\mathbf{a}$ linear and $\mathbf{b}$ trochoidal path with a $\mathbf{c}$ comparison of undeformed chip shapes

\section{Extension of a geometric physically-based simulation system}

In order to predict process forces during cutting operations, a geometric physically-based simulation system [9] was extended with a new tool model. The simulation system utilizes a time-step discretization of NC programs to calculate the TCP for cutting tools. For a given set of process parameter values, the $\mathrm{NC}$ program is subdivided into discrete time steps, which correspond to engagement situations along the given tool path. Instead of directly using the TCP to position a tool model, an interpolation along the trajectory of the cutting edge is applied [11, 25]. This is necessary due to the superposition of TCP and tool rotation. For each of these time steps, the swept envelope volume regarding the flank face shape of the tool was calculated. The swept volume was generated by connecting corresponding points of the flank face along the movement path of the cutting edge for two consecutive time steps (Fig. 5). The tool model is based on a structured grid which allows for an accessible assignment of isolated cutting segments along the tool [26]. The structured grid can be implemented as a triangular mesh, which enables numerically stable intersection tests with discrete workpiece representations [27]. The workpiece is modelled by using three perpendicular dexelboards, each with a defined spatial precision. The respective dexelboards are modeled using line segments arranged over a two dimensional grid, representing the volume of the workpiece [28]. Using these discrete models, the uncut chip thickness was approximated by calculating the discretized removed material intervals of the workpiece for every simulation step. These removed intervals were sub-sampled to discrete interval points, which were then projected to the corresponding cutting segments of the cutting edge to determine the uncut chip thicknesses per cutting segment (Fig. 5b).
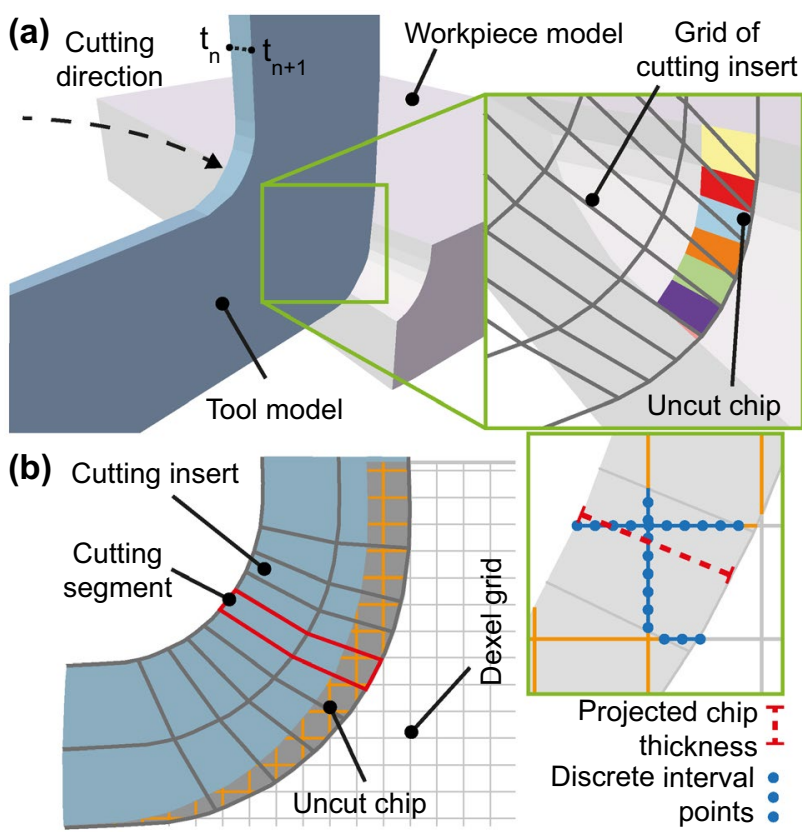

Fig. 5 Illustration of an exemplary generated envelope volume during intersection. a Time step discretization using a structured grid to determine the uncut chip. b Schematic of the determination of uncut chip thicknesses for each cutting-segment

\subsection{Consideration of tool topography and wear effects}

The representation of swept envelope volumes based on structured grid models enables the encoding of topography information of the flank face. As described in Sect. 2.3, the cutting inserts were digitized resulting in triangle meshes with approximately 100,000 triangles each. To only take the flank face into account, all non-visible triangles were culled by projecting each face in cutting direction. Based on the remaining vertices, a radial basis function with a cubic norm [29] was used to interpret the resulting scattered data for the construction of structured grid representations. 


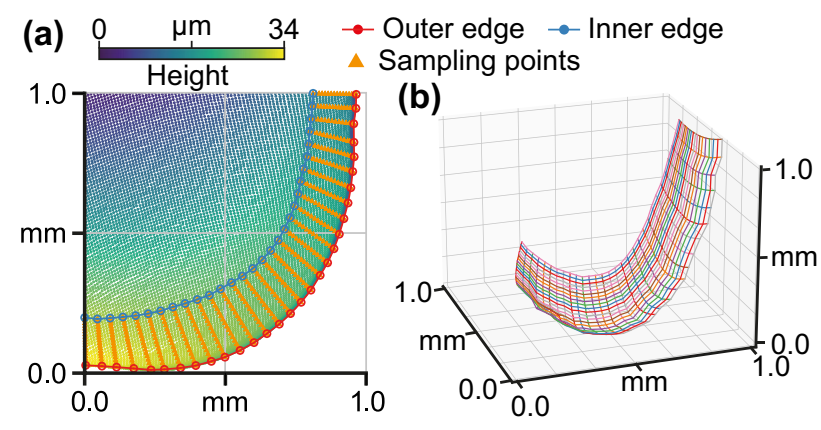

Fig. 6 Generation of sampling points. a Equidistant sampling of outer and inner contour with sampling points. b Resulting structural grid sampled from the radial basis function using determined control points

Since only limited regions of the cutting tool are engaged during the material removal process, the considered radial and axial depth of cut determine the engagements throughout the process. In this investigation, a width of $0.2 \mathrm{~mm}$ along the outer edge of the cutting insert was selected for further evaluation (Fig. 6a). Given these two contours along the cutting edge, a number of sampling points are distributed equidistantly to allocate a homogeneous distribution of cutting segments with individual widths $w_{s}$ for each segment, referred to as $\kappa$-discretization (Fig. 6a). Each of these segments are considered as distinct cutting edge segments. To incorporate the topographic features along the flank face, each segment is then extended with a number of sampling points in inward direction, referred to as $\tau$-discretization resulting in sub-segments. This structured grid approximation allows each sub-segment to be uniquely addressed with the indices $\kappa$ and $\tau$.

For evaluation, two different metrics were used to quantify each sub-segment. When projecting all sub-segments to the reference plane defined by the axial and radial tool directions (i.e. in cutting direction $v_{c}$ ), the local distance $\Delta_{p r o j}$ of each sub-segment to the outer edge can be computed. Additionally, the distance of each sub-segment $\Delta_{\text {para }}$ to the outer edge corresponding to the parametric representation of the shape of the segment is calculated (Fig. 7b). Since using only the projection in cutting direction would result in a distorted representation of the cutting edge (Fig. 7), a surrogate function based on the parametric representation is subdivided equidistantly to allow for a homogeneous discretization even along the corner radius and occuring abrasive tool wear. These computed point locations are used for the sampling of their projected height values by utilizing a radial basis function, which results in a structured grid mapping of the microand mesoscopic shape of the cutting edge (Fig. 6b). This approach enables the usage of arbitrary precision in radial
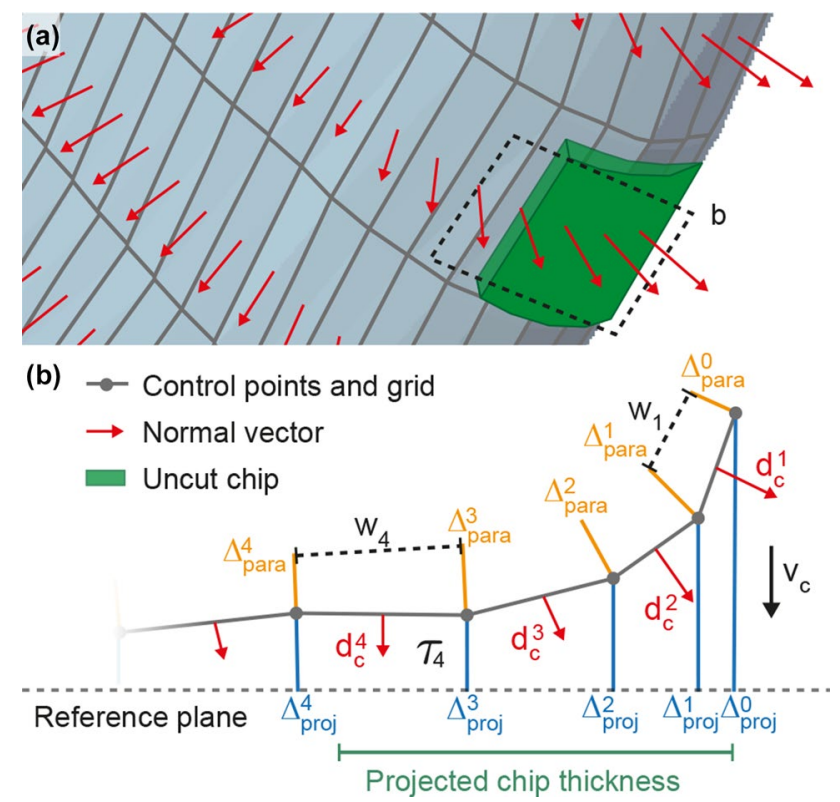

Fig. 7 Illustration of the calculation of the force direction $d_{c}$. a Closeup view of a structured grid representation including an uncut chip (green). b Depiction of the weighting factor $w_{i}$ for sub-segments based on the parametric distances $\Delta_{\text {para }}^{j}$ up to the highest sub-section denoted as $\tau_{4}$

and axial direction while ensuring a distinct assignment of each cutting segment and sub-segment when calculating chip thicknesses during the cutting process. This includes even very low chip thicknesses, which are associated to ploughing effects.

\subsection{Calculation of process forces}

While the calculation of process forces using empirical models in combination with undeformed chip thicknesses has been widely used $[9,11,20]$, the determination of force directions based on topographic information is a novel approach. By using a structured grid discretization, the force directions can be calculated for each cutting segment separately with respect to topographic features of the considered tool. To compensate for phenomenological effects like friction or ploughing, especially the topographic shape near the cutting edge is considered as well to contribute to the process forces. Using the normal direction of the facets in the structured grid, each sub-segment $i$ defines a local cutting direction $d_{c}^{i}$ for $i \in \kappa$ (Fig. 7a). Based on the calculated chip thicknesses $h$ for each simulation step, these directions are weighted to approximate the effective force direction. The weighting factors are approximated by the local width $w_{j}=\Delta_{\text {para }}^{j}-\Delta_{\text {para }}^{(j-1)}$ of each sub-segment for $j \in\left[1, \tau_{h}\right]$ where $\tau_{h}$ equals the highest index of a sub-segment in contact with 
the chip. The effective force direction $d_{e}$ can then be computed as

$d_{e}=\frac{d_{a}}{\left\|d_{a}\right\|}$ with $d_{a}=\sum_{j=0}^{\tau_{h}} w_{j} d_{c}^{j}$.

By weighting the directions, this approach also applies a geometric smoothing, which in turn compensates for deviations of normal vectors between sub-segments caused by sampling errors during digitization. The calculation using the aforementioned directions results in increased passive forces for very low chip thicknesses, whereas higher chip thicknesses show significant force amplitudes in cutting direction.

In order to incorporate characteristics in the area of the ploughing and separation zone, the calculated chip thickness is analyzed. By identifying all cutting sub-segments, which are at an angle above $\zeta=80^{\circ}$ to the cutting direction $v_{c}$, a surrogate ploughing chip thickness $h_{s}$ can be defined with $h_{s}<h$. By using the maximum projected distance $\Delta_{\text {proj }}^{i}$ of these sub-segments, the width of the surrogate chip thickness $h_{s}$ can be approximated, adding a supplementary force to the overall process forces.

This approximation of the effective direction regarding a given chip thickness $h$ and the supplementary chip thickness $h_{s}$ is then used to extend an empirical force model, resulting in

$F_{i}=w_{s} h^{(1-m)}\left(k_{c} d_{e}^{i}+k_{n} d_{n}^{i}\right)+w_{s} k_{c} v_{c}^{i} h_{s}^{(1-m)}$

for each cutting segment $i \in \kappa$, where $k_{c}, k_{n}$ and $m$ are empirical coefficients for the given tool-workpiece material combination. The normal direction $d_{n}$ equals the radial direction of the segment. The sum of all cutting segments results in the overall process force for a discrete time step.

For the digitized tool in a steady state $\left(V_{w, 1}\right)$, the coefficients $k_{c}, k_{n}$ and $m$ were determined using regression analysis of calculated and measured process force signals during partial face milling experiments with an L-BFGS-B optimization scheme [30]. In this particular case, regression resulted in parameter values $k_{c}=1926.08, k_{n}=502.64$ and $m=0.28$. To account for the deviations of process forces, a runout of $0.017 \mathrm{~mm}$ was applied. The simulated process forces show good accordance to measured process forces for the tool in the new state (Fig. 8a) with assumption of the runout error. When using the topography of the worn cutting-insert $\left(V_{w, 2}\right)$ with the same process force parameter values, the process forces show comparable changes of amplitudes in X-and Y-direction, whereby an increase of forces in $\mathrm{Z}$-direction is not reproduced (Fig. 8b). The difference in the length of the force signals are caused by slight differences in the runout errors of the worn inserts. Additionally, the cutting inserts could exhibit small variations regarding tool

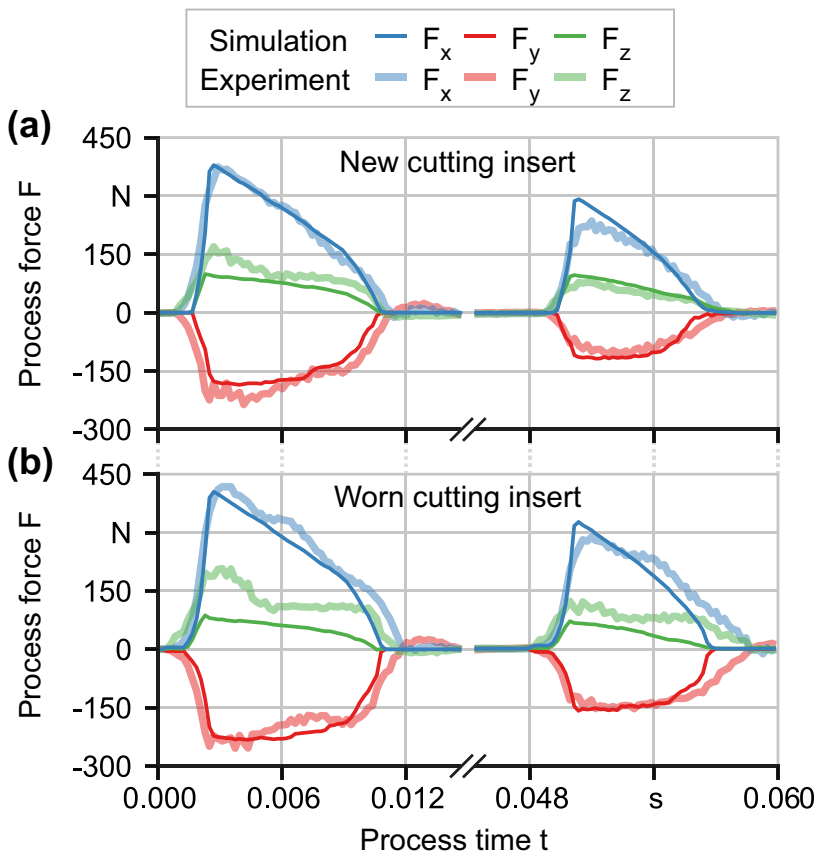

Fig. 8 Comparison of measured and calculated process forces for two consecutive tooth engagements using a the model of a new cutting insert with determined coefficients, $\mathbf{b}$ the model of a worn cutting insert, taking topographic changes into account

wear, which would result in differences in force characteristics. The overall shape and magnitude of forces, however, show a good agreement to measured process forces.

\section{Evaluation}

For the validation of the presented simulation approach, two force measurements of single arcs of a trochoidal milling path were selected from the milling experiments (Sect. 2). The first measurement is a single trochoidal path corresponding to a steady state stage of the cutting insert to validate the new cutting edge state after a material removal of approximately $V_{w}=1000 \mathrm{~mm}^{3}$. The second measurement was selected after machining of 135 paths with a material removal of approximately $V_{w}=6500 \mathrm{~mm}^{3}$, showing noticeable changes in force amplitudes (Fig. 9b). A comparable runout error can be observed, which corresponds to the previous considered worn state. The process forces showed an increase of force amplitudes of up to $30 \mathrm{~N}$. For these measurements, the first half of the arc (Fig. 9a (1)) was simulated in five exemplary regions along the path using the novel empirical force model taking topographic information into account (Fig. 10).

For the calculation of process forces, the modeled structured grids for a new and worn cutting inserts were used (Sect. 4.1). The runout was set to $R O_{\text {radial }}=0.013 \mathrm{~mm}$ and 


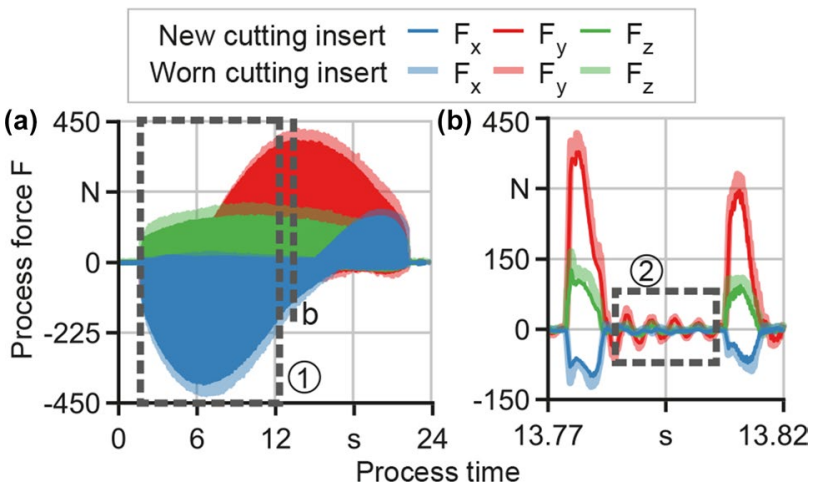

Fig. 9 Measured forces in X-, Y- and Z-direction for two different wear states. a Overview of one trochoidal arc. b Zoom on the difference of force amplitudes between two wear states

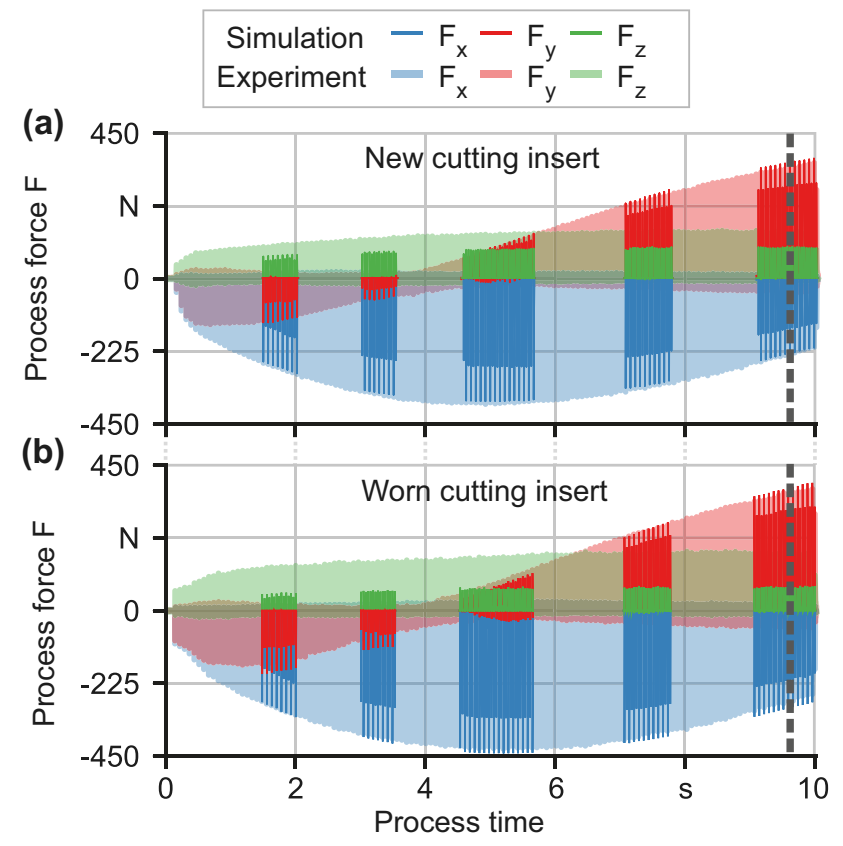

Fig. 10 Comparison of measured and simulated process forces for one arc of a trochoidal path. Experiments were conducted using a new cutting inserts and $\mathbf{b}$ worn cutting inserts, showing differences in force amplitudes in experiments and simulation results. The marked region (grey) is depicted in Fig. 11

$R O_{\text {axial }}=0.005 \mathrm{~mm}$, according to measurements conducted before milling experiments. The time discretization was set to 600 steps per tool rotation, resulting in a time-step of $\Delta_{t}=0.124 \mathrm{~ms}$. The discretization of the dexel grids was set to $0.005 \mathrm{~mm}$ in each direction, while the cut intervals were sub-sampled to $0.001 \mathrm{~mm}$ each to increase the chip sampling accuracy. The force coefficient values were set to $k_{c}=1926.08, k_{n}=502.64$ and $m=0.28$ as concluded in the initialization experiments (Sect. 4.2).
The calculated forces for the cutting insert in a new state show a good correspondence regarding the overall force progression for a trochoidal path (Fig. 10a) in Xand Y-direction. Process forces in Z-direction, however, were underestimated, which corresponds to the observed behaviour during initialization tests. Looking at two exemplary tooth engagements (Fig. 11a), a slight underestimation of the resulting contact length for the second tooth can be identified. This can be caused by small variations between cutting edges and minor differences in runout throughout the process. Overall, an equally good correspondence can be seen between measured and simulated process forces. Especially the differences of approx. $45 \mathrm{~N}$ in Z-direction are primarily seen at the beginning of the engagement. After initial contact, the force level is showing a good agreement. For the worn state of a cutting insert, a similar pattern in the overall force progression can be observed (Fig. 10b). While the force amplitudes show a good agreement for booth teeth (Fig. 11b), a slight deviation in $\mathrm{X}$ - and Y-direction, especially for the first tooth is noticeable after initial contact. These differences are caused by dynamic effects, as the force measurements are subjected to the transfer behaviour of the dynamometer. These variations can be observed between two tooth engagements (see Fig. 9b (2)). The second tooth exhibits a shorter contact length, presumed to be a deviation in runout error. The process forces in Z-direction are equally underestimated compared to the differences during the

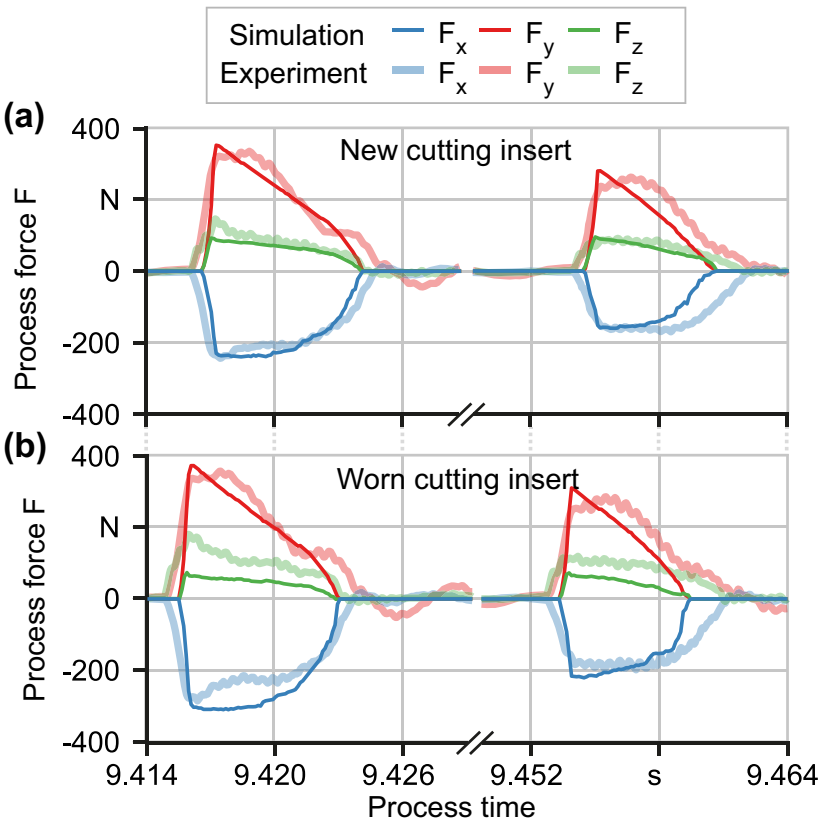

Fig. 11 Comparison of measured and simulated process forces for two exemplary tooth engagements using $\mathbf{a}$ new and $\mathbf{b}$ worn cutting inserts 
initialization experiment (Sect. 4.2). In summary, it can be concluded that an increase in the process forces due to a topographical change caused by tool wear could be reproduced successfully.

\section{Conclusions and outlook}

In this work, an extension of a time-domain simulation system was presented which enables the usage of digitized cutting edges for the prediction of process forces. With this extension, shape- and wear-specific information of cutting tools can be considered by structured grids. This was shown for cutting inserts, which were worn during milling of Inconel 718. The predicted process forces were determined with the extended process force model. Since runout can have a significant impact on the distribution of process forces when using multi-insert tools, the measured runout was applied for both tool wear states. For both wear states, a good accordance in linear path milling experiments could be achieved with one set of parameter values. Even when using non-linear strategies like in trochoidal milling experiments, which show high variance regarding chip thickness and engagement situations, the force prediction were still in good agreement with measured forces for both wear states. This methodology allowed wear-specific changes in process forces to be modeled without having to adjust force coefficients throughout the process. Slight deviations due to the occurrence of dynamic effects were neglected, as they did not play a decisive role in this investigation.

In future work, further investigations of model initialization will be conducted to ensure an increased approximation quality of process forces for cutting operations regarding different tool wear states, especially regarding the process forces occuring in Z-direction. An adaptive compensation of the runout error will be investigated to account for differences in contact length when using modular tool holders for cutting inserts.

Funding Open Access funding enabled and organized by Projekt DEAL.

\section{Declarations}

Conflict of interest The authors declare that they have no conflict of interest.

Open Access This article is licensed under a Creative Commons Attribution 4.0 International License, which permits use, sharing, adaptation, distribution and reproduction in any medium or format, as long as you give appropriate credit to the original author(s) and the source, provide a link to the Creative Commons licence, and indicate if changes were made. The images or other third party material in this article are included in the article's Creative Commons licence, unless indicated otherwise in a credit line to the material. If material is not included in the article's Creative Commons licence and your intended use is not permitted by statutory regulation or exceeds the permitted use, you will need to obtain permission directly from the copyright holder. To view a copy of this licence, visit http://creativecommons.org/licenses/by/4.0/.

\section{References}

1. Wu BH, Zheng CY, Luo M, He XD (2012) Investigation of trochoidal milling nickel-based superalloy. Mater Sci Forum 723:332-336. https://doi.org/10.4028/www.scientific.net/MSF. 723.332

2. Thakur A, Gangopadhyay S (2016) State-of-the-art in surface integrity in machining of nickel-based super alloys. Int J Mach Tools Manuf 100:25-54. https://doi.org/10.1016/j.ijmachtools. 2015.10.001

3. Ezugwu E, Wang Z, Machado A (1999) The machinability of nickel-based alloys: a review. J Mater Process Technol 86(1-3):116. https://doi.org/10.1016/S0924-0136(98)00314-8

4. Pleta A, Ulutan D, Mears L (2014) Investigation of trochoidal milling in nickel-based superalloy inconel 738 and comparison with end milling. In: International manufacturing science and engineering conference, vol 45813. American Society of Mechanical Engineers, New York, p V002T02A058

5. Sui S, Li Y, Shao W, Feng P (2016) Tool path generation and optimization method for pocket flank milling of aircraft structural parts based on the constraints of cutting force and dynamic characteristics of machine tools. Int J Adv Manuf Technol 85(5):1553-1564. https://doi.org/10.1007/s00170-015-8050-x

6. Potthoff N, Wiederkehr P (2021) Fundamental investigations on wear evolution of machining Inconel 718. Procedia CIRP 9:171-176

7. Attanasio A, Faini F, Outeiro J (2017) FEM simulation of tool wear in drilling. Procedia CIRP 58:440-444. https://doi.org/10. 1016/j.procir.2017.03.249

8. Fan Y-H, Wang T, Hao Z-P, Lan H, Cui R-R (2018) Research on tool wear based on multi-scale simulation in high speed cutting Inconel 718. Arch Civ Mech Eng 18:928-940. https://doi.org/ 10.1016/j.acme.2018.02.001

9. Wiederkehr P, Siebrecht T (2016) Virtual machining: capabilities and challenges of process simulations in the aerospace industry. Procedia Manuf 6:80-87. https://doi.org/10.1016/j. promfg.2016.11.011

10. Altintas Y, Kersting P, Biermann D, Budak E, Denkena B, Lazoglu I (2014) Virtual process systems for part machining operations. CIRP Ann 63(2):585-605. https://doi.org/10.1016/j.cirp. 2014.05.007

11. Denkena B, Pape O, Grove T, Mücke A (2019) Advanced process design for re-contouring using a time-domain dynamic material removal simulation. Procedia CIRP 79:21-26. https:// doi.org/10.1016/j.procir.2019.02.005

12. Siebrecht T, Kersting P, Biermann D, Odendahl S, Bergmann $\mathrm{J}$ (2015) Modeling of surface location errors in a multi-scale milling simulation system using a tool model based on triangle meshes. Procedia CIRP 37:188-192. https://doi.org/10.1016/j. procir.2015.08.064

13. Schmitz TL, Couey J, Marsh E, Mauntler N, Hughes D (2007) Runout effects in milling: surface finish, surface location error, and stability. Int J Mach Tools Manuf 47(5):841-851. https:// doi.org/10.1016/j.ijmachtools.2006.06.014

14. Odendahl S, Kersting P (2013) Higher efficiency modeling of surface location errors by using a multi-scale milling 
simulation. Procedia CIRP 9:18-22. https://doi.org/10.1016/j. procir.2013.06.161

15. Kienzle O (1952) Die bestimmung von kräften und leistungen an spanenden werkzeugen und werkzeugmaschinen. VDI-Z 94(11):299-305

16. Kolar P, Fojtu P, Schmitz T (2015) On cutting force coefficient model with respect to tool geometry and tool wear. Procedia Manuf 1:708-720. https://doi.org/10.1016/j.promfg.2015.09. 020

17. Zhu K, Zhang Y (2019) A generic tool wear model and its application to force modeling and wear monitoring in high speed milling. Mech Syst Signal Process 115:147-161

18. Hou Y, Zhang D, Wu B, Luo M (2014) Milling force modeling of worn tool and tool flank wear recognition in end milling. IEEE/ ASME Trans Mechatron 20(3):1024-1035

19. Otkur M, Lazoglu I (2007) Trochoidal milling. Int J Mach Tools Manuf 47(9):1324-1332

20. Niaki FA, Pleta A, Mears L (2018) Trochoidal milling: investigation of a new approach on uncut chip thickness modeling and cutting force simulation in an alternative path planning strategy. Int J Adv Manuf Technol 97(1):641-656. https://doi.org/10.1007/ s00170-018-1967-0

21. Pleta A, Niaki FA, Mears L (2018) A comparative study on the cutting force coefficient identification between trochoidal and slot milling. Procedia Manuf 26:570-579

22. Ulutan D, Ozel T (2011) Machining induced surface integrity in titanium and nickel alloys: a review. Int J Mach Tools Manuf 51(3):250-280. https://doi.org/10.1016/j.ijmachtools.2010.11.003

23. Rauch M, Duc E, Hascoet J-Y (2009) Improving trochoidal tool paths generation and implementation using process constraints modelling. Int J Mach Tools Manuf 49(5):375-383. https://doi. org/10.1016/j.jimachtools.2008.12.006
24. Salehi M, Blum M, Fath B, Akyol T, Haas R, Ovtcharova J (2016) Epicycloidal versus trochoidal milling-comparison of cutting force, tool tip vibration, and machining cycle time. Procedia CIRP 46:230-233. https://doi.org/10.1016/j.procir.2016.04.001

25. Wiederkehr P, Wilck I, Siebrecht T (2020) Determination of the dynamic behaviour of micro-milling tools at higher spindle speeds using ball-shooting tests for the application in process simulations. CIRP Ann 69(1):97-100. https://doi.org/10.1016/j.cirp.2020.04. 036

26. Liseikin VD (1999) Grid generation methods, vol 1. Springer, Berlin. https://doi.org/10.1007/978-90-481-2912-6

27. Meijer A, Bergmann JA, Krebs E, Biermann D, Wiederkehr P (2019) Analytical and simulation-based prediction of surface roughness for micromilling hardened HSS. J Manuf Mater 3(3):70. https://doi.org/10.3390/jmmp3030070

28. Müller H, Surmann T, Stautner M, Albersmann F, Weinert K (2003) Online sculpting and visualization of multi-dexel volumes. In: Proceedings of the eighth ACM symposium on solid modeling and applications, pp 258-261. https://doi.org/10.1145/781606. 781646

29. Gutmann H-M (2001) A radial basis function method for global optimization. J Glob Optim 19(3):201-227. https://doi.org/10. 1023/A:1011255519438

30. Zhu C, Byrd RH, Lu P, Nocedal J (1997) Algorithm 778: L-BFGS-B: Fortran subroutines for large-scale bound-constrained optimization. ACM Trans Math Softw 23(4):550-560. https://doi. org/10.1145/279232.279236

Publisher's Note Springer Nature remains neutral with regard to jurisdictional claims in published maps and institutional affiliations. 